\title{
Environmental Risk Factor
}

National Cancer Institute

\section{Source}

National Cancer Institute. Environmental Risk Factor. NCI Thesaurus. Code C18244.

Health hazards at home, in the work place, or in nature (e.g., infectious agents, irritants, respiratory fibrotic agents, asphyxiants, allergens, metabolic poisons, physical agents, mutagens, teratogens, and carcinogens). (Winett et al: Health Psychology and Public Health) 